\title{
Land-cover mapping using multitemporal, dual-frequency polarimetric SAR data
}

\section{Skriver, Henning; Schou, Jesper; Dierking, Wolfgang}

\section{Published in:}

Proceedings of Geoscience and Remote Sensing Symposium

Link to article, DOI:

10.1109/IGARSS.2000.860509

Publication date:

2000

Document Version

Publisher's PDF, also known as Version of record

Link back to DTU Orbit

Citation (APA):

Skriver, H., Schou, J., \& Dierking, W. (2000). Land-cover mapping using multitemporal, dual-frequency polarimetric SAR data. In Proceedings of Geoscience and Remote Sensing Symposium (Vol. 1, pp. 331-333). IEEE. https://doi.org/10.1109/IGARSS.2000.860509

\section{General rights}

Copyright and moral rights for the publications made accessible in the public portal are retained by the authors and/or other copyright owners and it is a condition of accessing publications that users recognise and abide by the legal requirements associated with these rights.

- Users may download and print one copy of any publication from the public portal for the purpose of private study or research.

- You may not further distribute the material or use it for any profit-making activity or commercial gain

- You may freely distribute the URL identifying the publication in the public portal 


\title{
Land-Cover Mapping Using Multitemporal, Dual-Frequency Polarimetric SAR Data
}

\author{
Henning Skriver, Jesper Schou, and Wolfgang Dierking \\ Danish Center for Remote Sensing, Dept. Electromagnetic Systems \\ Technical University of Denmark, Building 348, DK-2800 Lyngby, Denmark \\ Phone: +45 458814 44, Fax: +45 459316 34, E-mail: hs@emi.dtu.dk ${ }^{1}$
}

The Danish Center for Remote Sensing (DCRS) is, in collaboration with the Danish mapping agency, conducting a study on topographic mapping using SAR data, and land cover mapping results are presented. The Danish EMISAR system (an L- and C-band, fully polarimetric, airborne SAR) have in 1994 to 1999 during the growing season acquired a lot of data over a Danish agricultural site. The data acquisitions were co-ordinated with ground surveys to obtain a detailed land cover map. The test area contains a large number of different land cover classes, such as more than 10 different crop types, deciduous and coniferous forest types, wetlands, lakes, and urban areas. The data are used to study the classification potential of polarimetric SAR data using the Wishart distributed covariance matrix..

\section{INTRODUCTION}

The potential of synthetic aperture radar (SAR) for landcover mapping applications has since long time been identified. The main advantage of the SAR is its all-weather mapping capabilities, which secures the mapping independent of cloud cover, that may prevent acquisition by optical and infrared sensors. Furthermore, the backscattering is sensitive to the structure and dielectric properties of the targets[1]. These properties are normally very different for most of the land-cover classes.

Various classification methods have been applied to polarimetric SAR data to obtain land-cover information, e.g. knowledge-based classification [2], neural network classification [3], wavelets [4], maximum likelihood classification [5] and a combined knowledge-based/maximum likelihood scheme [6]. The common conclusion from the studies is that the polarimetric data enhance the classification performance.

In the present study the Danish airborne dual-frequency polarimetric SAR, EMISAR, has been used [7]. Previously the classification potential has been assessed for agricultural crops using the linear polarizations $\mathrm{HH}, \mathrm{VV}, \mathrm{HV}$ in various combinations, e.g. single polarization, multi-polarization, multi-frequency and multitemporal [8] and using the full polarimetric information [9], i.e. using the covariance matrix. These results showed an improvement of the classification results using the full polarimetric information. In this paper the analysis is extended to cover land-cover classification using the full polarimetric information.

\section{DATA ACQUISITION}

The EMISAR has been developed at the Department of Electromagnetic Systems (EMI) of the Technical University of Denmark, and it is an L- and C-band fully polarimetric and interferometric SAR. The SAR system is installed on a Danish Air Force Gulfstream aircraft G-3. The SAR system is normally operated from an altitude of approximately $12.500 \mathrm{~m}$, the one-look spatial resolution is $2 \mathrm{~m}$ by $2 \mathrm{~m}$, and the ground range swath is approximately $12 \mathrm{~km}$. The processed data from this system are fully calibrated by using an internal calibration system.

A large number of acquisitions with both the C- and Lband polarimetric SAR has been carried out from 1994 to 1998 over a Danish agricultural test site. In 1998 simultaneous L- and C-band data were acquired on 21 March (80), 17 April (107), 20 May (140), 16 June (167), 15 July (196) and 16 August (228), where the numbers in parenthesis are the corresponding Julian Day. All acquisitions have been co-registered by identifying ground control points in the images and using an interferometric DEM acquired by the EMISAR system, as described in [10]. Before the resampling, the original one-look scattering matrix data have been transformed to covariance matrix data, and these data have been averaged to reduce the speckle by a cosine-squared weighted 9 by 9 filter. The new pixel spacing in the images is $5 \mathrm{~m}$ by $5 \mathrm{~m}$. From homogenous areas in the images the equivalent number of looks is estimated to approximately 10 and that corresponds to a standard deviation for the backscatter coefficient of approximately $1.5-2.0 \mathrm{~dB}$.

The test site contains a large number of agricultural fields with different crops, as well as several lakes, forests, areas with natural vegetation, grasslands, and urban areas. The area is relatively flat, and corrections of the local incidence angle due to terrain slope are therefore not necessary. The crop types present in the area are spring barley, winter barley, winter wheat, rye, oats, winter rape, maize, peas, potatoes, and beets, where spring barley, winter barley, winter wheat and peas are the most frequent crop types. A land cover map was established for the test site including more than 200 fields covering different incidence angles.

\section{METHOD}

The polarimetric SAR measures the amplitude and phase of the backscattered signals in the four combinations of the

\footnotetext{
${ }^{1}$ The work has been supported by the Danish ESA Follow-on Research Board. The data acquisition and processing has been supported by the Danish National Research Foundation.
} 
linear receive and transmit polarizations hh, hv, vh and vv. These signals form the complex scattering matrix $\mathbf{S}$, where the elements $S_{p q}$ are the complex scattering amplitudes for receive polarization $p$ and transmit polarization $q$ ( $p$ and $q$ are either $v$ for vertical or $h$ for horizontal). In the case of reciprocity which normally applies for natural targets we have $S_{h v}=S_{v h}$. In the above-mentioned averaging the covariance matrix is formed for each averaged pixel:

$$
\langle\mathrm{C}\rangle=\left\{\begin{array}{lll}
\left\langle S_{h h} S_{h h}^{*}\right\rangle & \left\langle S_{h h} S_{h v}^{*}\right\rangle & \left\langle S_{h h} S_{v v}^{*}\right\rangle \\
\left\langle S_{h v} S_{h h}^{*}\right\rangle & \left\langle S_{h v} S_{h v}^{*}\right\rangle & \left\langle S_{h v} S_{w v}^{*}\right\rangle \\
\left\langle S_{v v} S_{h h}^{*}\right\rangle & \left\langle S_{w} S_{h v}^{*}\right\rangle & \left\langle S_{v} S_{v v}^{*}\right\rangle
\end{array}\right\}
$$

where $\propto$ denotes ensemble averaging, and * denotes complex conjugation.

The classification performed is based on the Bayes maximum likelihood classification scheme using the covariance matrix which is Wishart distributed [11]. Assuming that the data are statistically independent between the acquisitions and between the frequencies, the generalized distance measure is [11]

$$
d\left(\mathbf{Z}, \omega_{m}\right)=\sum_{j=1}^{J} n\left\{\ln \left|\mathbf{C}_{m}(j)\right|+\operatorname{Tr}\left[\mathbf{C}_{m}(j)^{-1} \mathbf{Z}(j)\right]\right\}-\ln \left[P\left(\omega_{m}\right)\right](2)
$$

where $C_{m}(j)$ is the feature covariance matrix of the $m^{\text {th }}$ class in the $j^{\text {th }}$ acquisition, $Z(j)$ is the covariance matrix of the $j^{\text {th }}$ acquisition for the pixel to be classified, $n$ is the number of looks, $\mathrm{P}\left(\omega_{\mathrm{m}}\right)$ is the a priori probability for class $\mathrm{m}, \mathrm{Tr}$ denotes the trace, and $J$ is the total number of acquisitions.

One relatively large area (more than 500 pixels) has been picked for each of the above-mentioned crops, for a coniferous forest area, for a deciduous forest area, for a grass area, for a lake area and for a village area. These areas have been used as training areas for the classifier, i.e. used to estimate the feature covariance matrix in (2). The pixels in the training areas have been classified and the classification accuracy estimated. The interpretation of these results must take into account that such results are slightly optimistic.

\section{RESULTS}

Each of the 12 images (6 L-band and 6 C-band images) has been classified using the procedure outlined in the previous section. In addition, for each of the 6 acquisitions a classification result was obtained for a combination of the two frequencies L- and C-band using (2). For each classification the 15 land-cover classes listed above were used. After the classification these classes were combined into 6 major classes: crops, coniferous forest, deciduous forest, grassland, lake and village. In Figs. 1-3 the classification errors for these 6 classes for each acquisition are shown for L-band data, C-band data, and L- and C-band data combined, respectively.

The classification errors are seen to be relatively constant, i.e. independent of acquisition time. The only exception from this is the increase of the classification error for forest at
C-band from May to July, especially the deciduous forest class shows a dramatic increase. The reason is probably the effect of the foliage, that makes the discrimination of the trees from some of the other vegetation classes difficult at $\mathrm{C}$ band. The best classification performance is seen for the lake and the crop classes, which in all three cases have a rather small classification error. The worst result is seen for the village class, where classification errors above $90 \%$ are seen in some cases. Poor results for urban areas have also been reported elsewhere, e.g. [4][5]. Urban areas consist of many different target classes, e.g. trees and buildings, and therefore they are normally difficult to classify. We observe an overall better performance when the $\mathrm{L}$ - and C-band data are combined in the classification, only the urban class is still poorly classified. If only a single acquisition is possible, an acquisition in end of April/beginning of May seems to be optimum. A slightly better performance is seen at L-band compared with C-band.

\section{CONCLUSIONS}

An analysis has been performed of the classification potential for land-cover mapping applications of polarimetric, dual-frequency, multitemporal SAR data. The classification performance for single acquisition L-, C-, or combined Land C-band data has been analysed. The performance is improved by the combination of the two frequencies. The urban class is in all cases poorly classified.

\section{REFERENCES}

[1] Ulaby, F. T., R. K. Moore, and A. K. Fung, 1986, Microwave Remote Sensing: Active and Passive, vol. MII, Dedham, MA: Artech House.

[2] Pierce, L.E., F.T. Ulaby, K. Sarabandi, and M.C. Dobson, 1994 "Knowledge-based classification of polarimetric SAR images", IEEE Trans. Geosci. Remote Sens., vol. 32, pp. 1081-1086.

[3] Ito, Y, and S. Omatu, 1997, "Land cover mapping method for polarimetric SAR data", SPIE, vol. 30702, pp. 388-397.

[4] Nagai, T., Yamaguchi, Y., Yamada, H., 1994, "Use of multipolarimetric enhanced images in SIR-CIX-SAR land-cover classification", IEEE Trans. Commun., vol. E80-B, pp. 1696-1702.

[5] Smith, A.J.E, A.C. van der Broek, and R.J. Dekker., 1998, "Landuse classification using PHARUS polarimetric SAR", Second int workshop on Retrival of Bio- and Geophysical Parameters from SAR data for land applications.

[6] Pierce, L.E., K.M. Bergen, M.C. Dobson, and F.T. Ulaby 1998, "Multitemporal land-cover classification using SIR-C/X-SAR imagery", Remote Sens. Environ.., vol. 64, pp. 20-33.

[7] Christensen, E. L., N. Skou, J. Dall, K. Woelders, A. Netterstrom, J.H. Jorgensen, J. Granholm, and S.N. Madsen, 1998, "EMISAR: Polarimetric L- and C-band SAR", IEEE Trans. Geosci. Remote Sens., vol. 36, pp. 1852-1865.

[8] Skriver, H., M.T. Svendsen, and A. Thomsen, 1997, "Crop Monitoring by the dualfrequency, polarimetric EMISAR", Proc. Third Int. Airborne Rem. Sens. Conf. and Exh., pp. II-753 - II-760.

[9] Skriver, H., M. T. Svendsen, F.N. Nielsen, and A. Thomsen, 1999 "Crop classification by polarimetric SAR", IEEE Intenational Geoscience and Remote Sensing Symposium, 1999, pp. 2333-2335.

[10] Dierking, W, J. Schou, and H. Skriver, "Change Detection of Small Objects and Linear Features in Multi-Temporal Polarimetric Images", IEEE Intenational Geoscience and Remote Sensing Symposium, 2000, these proceedings.

[11] Lee, J.S., and M.R. Grunes, 1994, "Classification of multi-look polarimetric SAR imagery based on complex Wishart distribution", Int. J. Rem. Sens., vol. 15, pp. 2299-2311. 


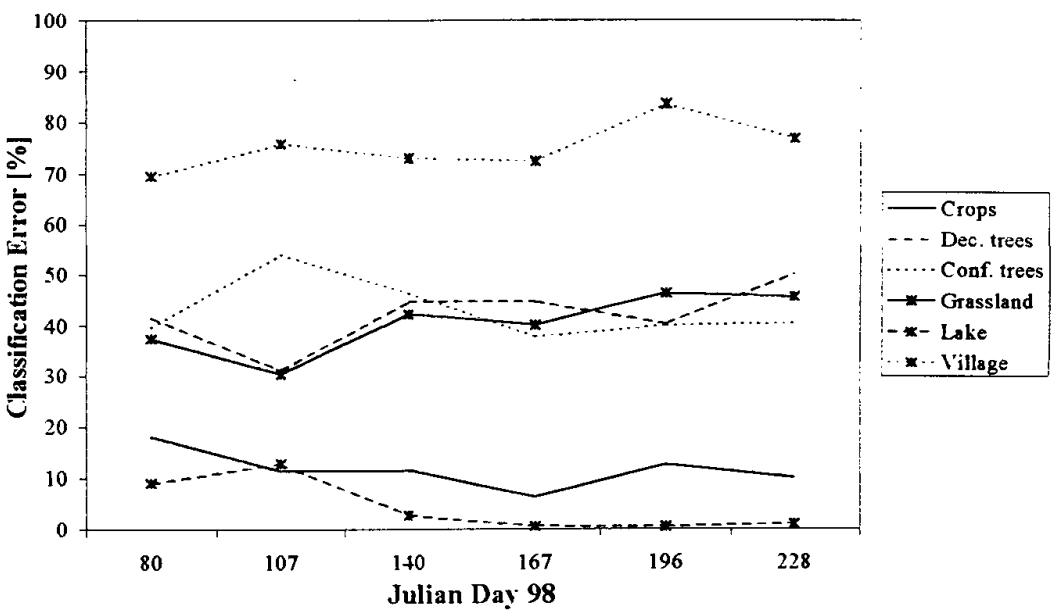

Fig. 2 Classification errors using C-band polarimetric SAR data
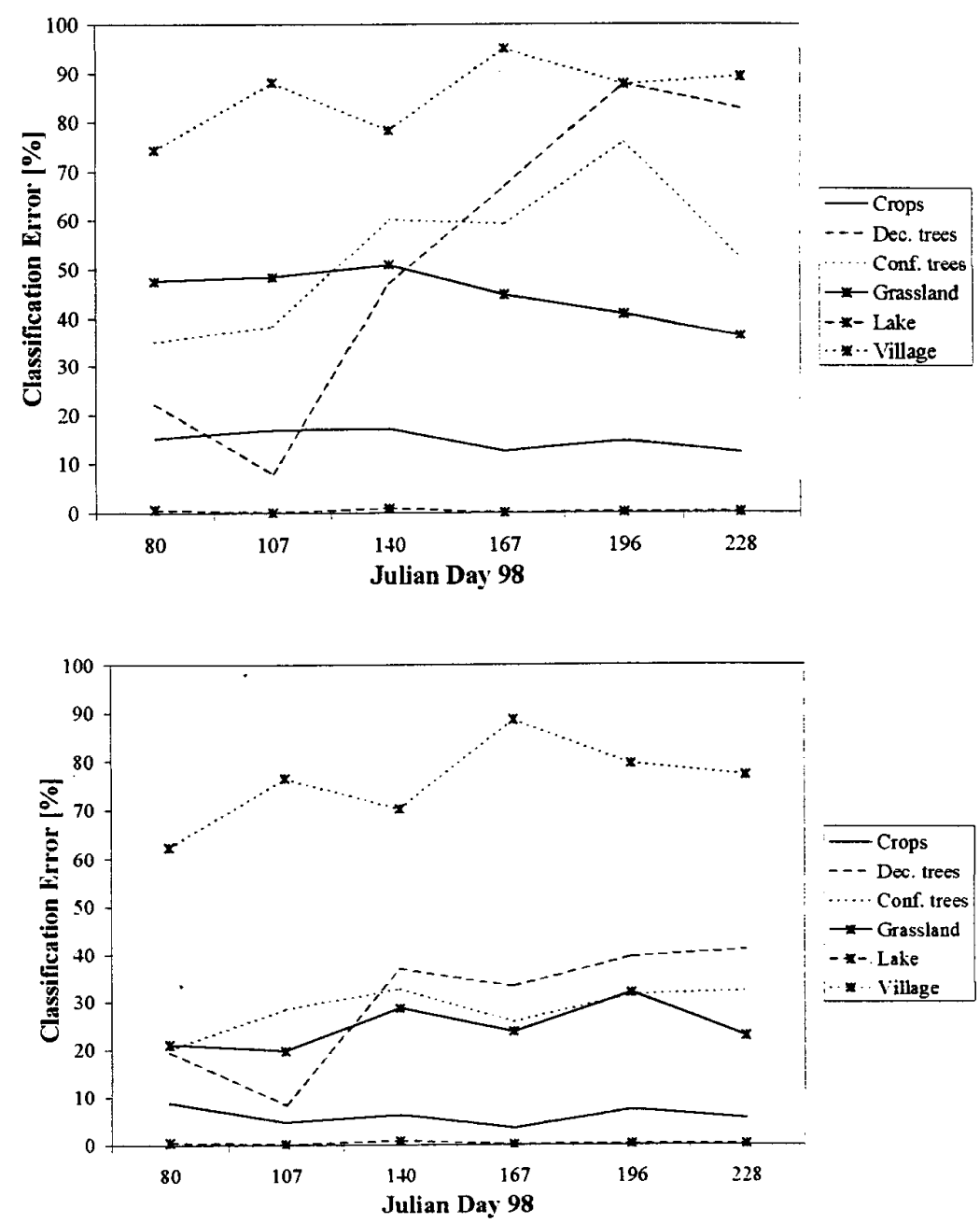